\title{
Socially Acceptable Behavior
}

W hile perusing the "popular" section of the social bookmarking site del.icio.us recently, I was struck by the myriad off-the-wall sites that users are bookmarking. Indeed, one of the most popular sites (311 bookmarks!) was titled, "Vanishing Point: How to disappear in America without a trace."

Of course, there were lots of other sites listed that are much more technically relevant to my life, but I was intrigued enough by this particular site to check it out-not that I'm planning on making my great escape. But now I can say with all honesty that if I ever do need to disappear, I have the knowledge to make it happen.

All kidding aside, the whole episode made me take notice of how much del.icio.us and other social bookmarking sites are being used as a resource for everything from the rules of grammar to the ins and outs of XML. It's as if those in the know have created their own personal library in which they can access every manual, every how-to book, every piece of reference material they would ever need. Could this be the death of the public library system as we know it? I doubt it. The same dire prediction was made when the Internet became ubiquitous, but rather than plan their own funeral, savvy librarians adopted the Internet as an integral part of their resources.

Social bookmarking hasn't even gone mainstream yet. One can only imagine the relevant (and, yes, probably a lot of irrelevant) information that will be bookmarked once the huddled masses adopt the technology.

One thing is for sure: Social bookmarking is a technology whose time has come, and once corporate America discovers it, advertising will surely follow. I give del.icio.us eight months before it becomes riddled with ads.

The implications of social bookmarking are many, and some are not so obvious. Marketers can use social bookmarking sites to collect all kinds of demographic information from a user's personal bookmarks, then "personalize" that user's advertising experience (one can only imagine the companies advertising to those who have bookmarked the "Vanishing Point" site referenced above). The result would be a much more effective advertising campaign by the vendor than the current scattershot methods, and those social bookmarking sites could in

\section{Social bookmarking}

IS A TECHNOLOGY

WHOSE TIME HAS COME.

turn charge much more for their advertising space. An interesting proposition if you're a company looking to target a niche audience.

But could social bookmarking work within the walls of an enterprise? Could a company offer social bookmarking as a reference tool on its intranet, allowing developers, sales executives, janitors, and engineers alike to create their own (or department) repositories for information relevant to their jobs? This could mean the end of the reference manual, as well as the three-hour meeting in which two of those hours are spent reviewing a project's progress. Make the project notes and reference manuals available as bookmarks on the intranet, and that meeting time and brainpower could be put to better use.

The success of such an endeavor, however, lies in the execution. The same could be said of most big ideas, but social bookmarking has the power to do real good if used correctly and effectively.

David Millen, Jonathan Feinberg, and Bernard Kerr delve into this very subject in this month's issue. In their article, "Social Bookmarking in the Enterprise," Millen and Co. discuss the pros and cons of such an arrangement for the enterprise audience.

Also of note in this month's issue is a one-on-one with Microsoft CTO Ray Ozzie, creator of Lotus Notes and founder of Groove Networks, an upstart in the peerto-peer space that was purchased by Microsoft last year. Ozzie was recently tapped to execute a software services strategy across Microsoft's three new business divisions-a daunting task as Microsoft plays catch-up with the rest of the software-as-service world. Ozzie discusses the importance of collaborative software in Microsoft's future.

I hope you find this month's issue to be as interesting as I did. But then again, I'm a social person. So please continue to send your comments to me at cohanlon@acmqueue.com.Q

CHARLENE O'HANLON, editor and publisher of ACM Queue, is no stranger to social bookmarking. But she can't figure out how to get to level 5 on Super Mario Brothers 3. 